\title{
Momchil Manov
}

E-mail:m.manov@nvna.eu

Naval Academy "N. Y. Vaptsarov", Varna

Bulgaria, Varna, P.C. 9026,73 Vassil Drumev St.

\section{Investigation of Morphology of Ti-6Al-7Nb after sulphuric anodizing}

\begin{abstract}
Titanium alloys possess unique combination of good mechanical properties and excellent corrosion resistance which make them an attractive material for application in many engineering areas. Along with these properties there are some disadvantages which can be eliminated successfully using different surface treatment methods. One of the most commonly used among them is anodizing. This article presents investigation of the results obtained from anodizing titanium alloy Ti-6Al-7Nb using sulphuric acid. The quality assessment and morphology of the anodized layer is made using a micro structural analysis, EDS analysis, XRD analysis and microhardness measurements.
\end{abstract}

Keywords: titanium alloys, surface modification, Ti-6Al-7Nb, sulphuric anodizing, surface morphology

\section{Introduction}

Titanium alloys have the prospect to be used in various areas because of their advantages over other construction materials. Ti-6Al-4V and Ti-6Al-7Nb are highstrength titanium alloys with numerous applications in modern industry. In recent times most engineers prefer to use Ti-6Al-7 $\mathrm{Nb}$ because of the questionable toxicity of element vanadium in Ti-6Al-4V [1,2,3].

The application of titanium alloys in general and of Ti-6Al-7 $\mathrm{Nb}$ is still limited in specific sectors in maritime industry because of the old dominant concept that titanium alloys are exotic expensive materials with complex technologies for machining and surface treatment. Nowadays titanium alloys are used for production of machine parts, which are subjected to high temperature and aggressive fluids such as pipes, heat exchangers, gas turbines, pump impellers, valves, hull construction elements, electronic components etc. [13]. 
Main advantages of titanium alloys are [13]:

- excellent corrosion resistance in the sea water and other aggressive media;

- non-toxic to humans and environment;

- excellent strength characteristics;

- non magnetic;

- good shaping and welding capabilities;

- good casting properties and machining through plastic deformation.

Along with the advantages, titanium alloys possess some drawbacks in terms of mechanical properties. Low hardness and poor tribological properties limit application of titanium alloys in the production of machine parts, which are subjected to friction and surface contact loads. In response, there has evolved the development of new prospective surface modification technologies. This fact provides the opportunity for introduction of new advanced methods for obtaining modified surface layers with unique properties and they successfully eliminate the existing disadvantages $[4,7,13]$.

One of the most prospective and widely used electrochemical methods for surface modification of titanium alloys is anodizing. Anodic films have been of great interest due to their high possibilities for industrial applications. Depending on the particular type of anodizing process used, the resulting anodic coatings provide improved wear resistance, corrosion protection and improved adhesive properties [5,6,8,11].

In this paper, sulphuric anodizing of Ti-6Al-7Nb will be conducted. The goal of the investigation process is to define how this surface modification method affects the morphology and microhardness profile of Ti-6Al-7Nb. The results of the investigation will give a foundation for more researches to be made in terms of expanding the application of titanium alloy Ti-6Al-7Nb.

\section{Experimental Details}

\subsection{Sample preparation}

Some important properties of the investigated titanium alloy Ti-6Al-7Nb are given in Table $1[9,10,12]$. 
Table 1 Properties of Ti-6Al-7Nb

\begin{tabular}{|l|c|c|}
\hline \multicolumn{1}{|c|}{ Property } & Value & Unit \\
\hline Density & $\mathrm{g} / \mathrm{cm}^{3}$ & 4.52 \\
\hline Compressive Strength & $\mathrm{MPa}$ & 1086 \\
\hline Fracture Toughness & $\mathrm{MPa} \cdot \mathrm{m}^{1 / 2}$ & 75 \\
\hline Hardness & $\mathrm{MPa}$ & 2900 \\
\hline Tensile Strength & $\mathrm{MPa}$ & 1005 \\
\hline Young's Modulus & $\mathrm{GPa}$ & 110 \\
\hline Melting Point & $\mathrm{K}$ & 1860 \\
\hline Thermal Conductivity & $\mathrm{W} / \mathrm{m} . \mathrm{K}$ & 8 \\
\hline Thermal Expansion & $10^{-6} / \mathrm{K}$ & 9.8 \\
\hline Corrosion resistance $(\mathrm{NaCl})$ & $\mathrm{g} / \mathrm{cm}^{2}$ & $0.6 .10^{-4}$ \\
\hline
\end{tabular}

Commercially available Ti-6Al-7 $\mathrm{Nb}$ samples are used for conducting the experimental procedure. The cylindrical samples used have the following dimensions: $\mathrm{d}=10 \mathrm{~mm}, \mathrm{~h}=5 \mathrm{~mm}$. The calculated total surface, subjected to anodizing for each sample is $\mathrm{S}=314 \mathrm{~mm}^{2}$. Sample preparation includes surface treatment with nitric and hydrofluoric acid solution for 20 s and further cleaning with acetone liquid. The final surface preparation treatment is rinsing with running water for 3 minutes followed by drying.

\subsection{Anodizing process conduction}

The prepared samples are subjected to anodizing using SIFCO SP30 equipment at voltage $20 \mathrm{~V}$ and amperage $7.33 \mathrm{Amph}$ for $20 \mathrm{~min}$. The anodizing media is sulphuric acid solution type II (according to SIFCO anodizing instruction manual) [11]. The temperature of the anodizing media is constantly maintained at $-4^{\circ} \mathrm{C}$. During the experimental procedure conduction, the medium is circulating constantly by means of circulation pump in a specialized container where the anodizing process is conducted.

\section{Results and discussion}

\subsection{Micro structural analysis}

The microstructure of anodized samples is investigated using optical microscope (Nikon Eclipse L150). For metallographic observation the specimen's cross-sections were ground and polished. The morphology of coatings is investigated using a scanning electron microscope (SEM Joel, JSM 6060-LU).

After the completion of the anodizing process, a change in the surface colour of the anodized samples is indicated. This is due to a change occurred in the surface layer composition during the anodizing process. The cross section of the anodized samples 
is shown in Figure 1. It can be defined as formation of the anodized surface layer with an average thickness of $4 \mu \mathrm{m}$.
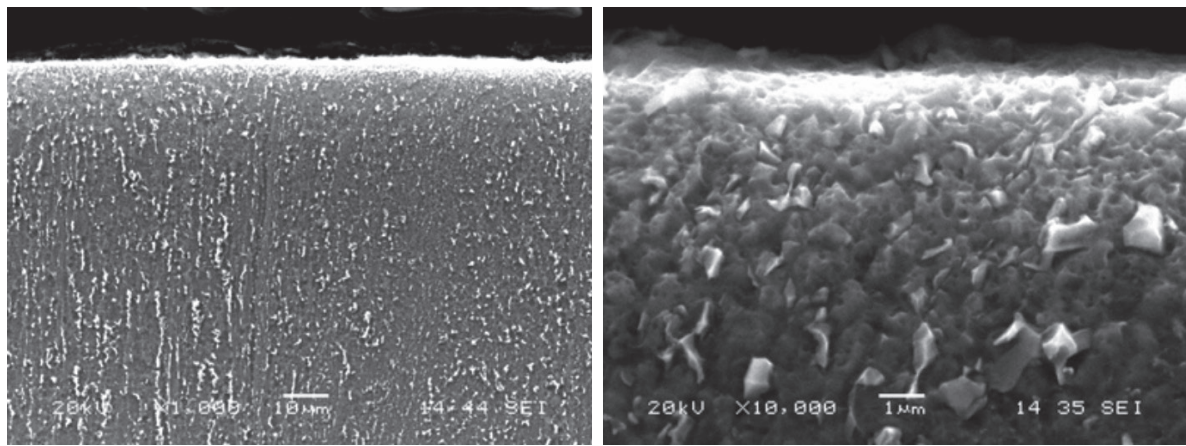

Figure 1 SEM images of anodized Ti-6Al-7Nb

\subsection{Anodized surface layer characterization}

The elemental distributions are measured by energy dispersive spectroscopy (EDS, Joel, JSM 6060-LU). The phase composition is determined using X-ray diffraction (XRD, 600 Rigaku X-Ray Diffraction D/MAX/2200), using $\mathrm{Cu}-\mathrm{K} \alpha$ radiation in $20-100^{\circ}(2 \theta)$.

The results from the EDS are shown in Figure 2. Presence of the main alloying elements of Ti-6Al-7 $\mathrm{Nb}$ can be indicated in relation to their concentration. The EDS analysis didn't indicate any presence typical for anodizing process $\mathrm{TiO}_{\mathrm{x}}$.

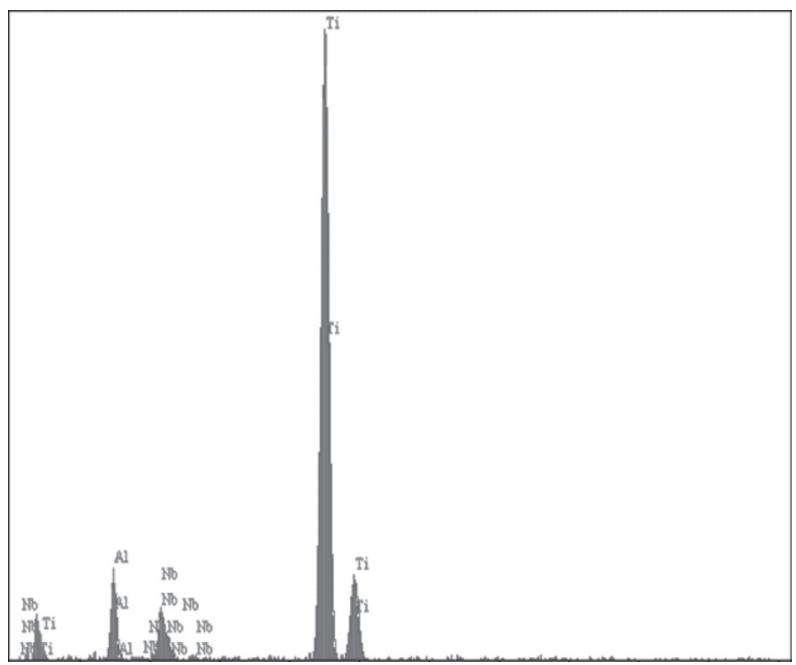

Figure 2 Results from EDS analysis of the anodized Ti-6Al-7Nb sample 


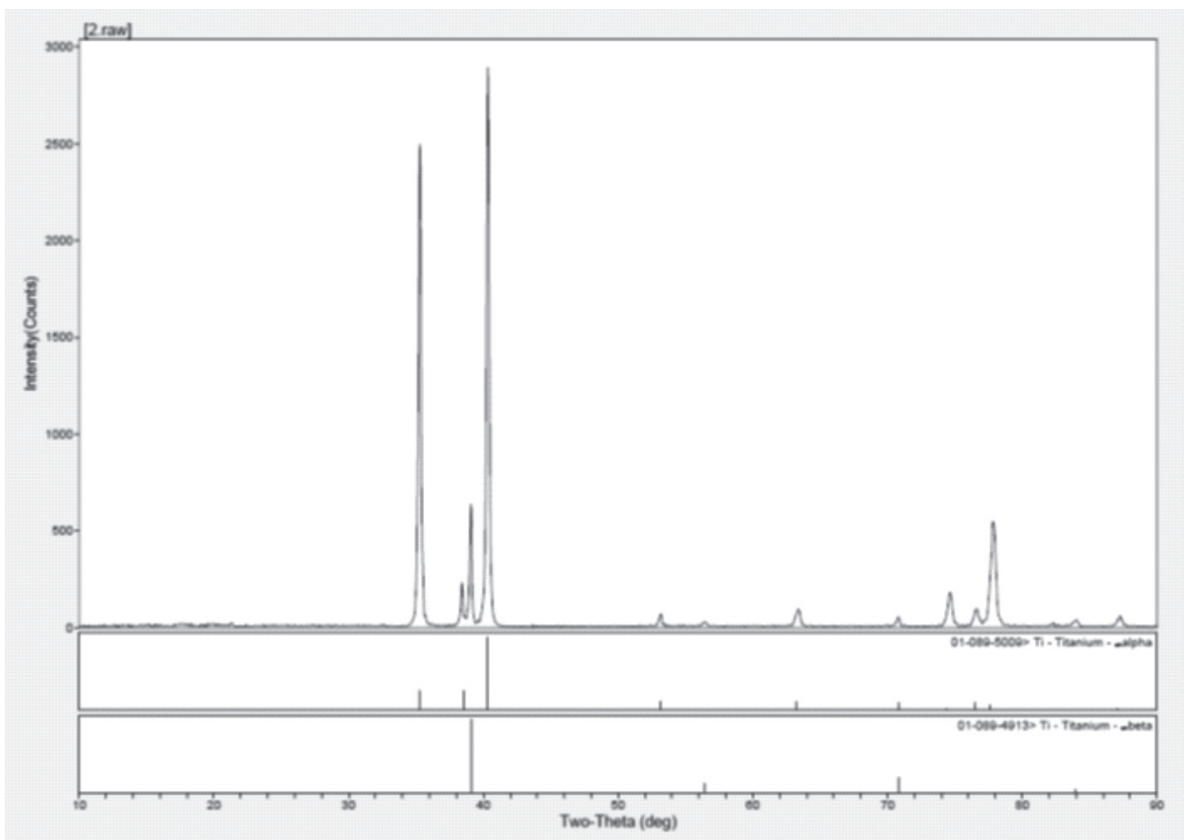

Figure 3 Results of XRD analysis of the anodized Ti-6Al-7Nb sample

The phase composition of the anodized samples is shown in Figure 3. The XRD analysis shows that the composition of the surface anodized layer is $\alpha$-Ti and $\beta$-Ti. This surface layer composition can be explained with the specific processes running through the experimental procedure conduction. The following interactions in the Ti$6 \mathrm{Al}-7 \mathrm{Nb}$ samples, during the anodizing process in sulphuric acid solution are conducted $[4,5,7,9,10,11]$ :

$$
\mathrm{Ti}_{2} \mathrm{O}_{3}+6 \mathrm{H}^{+}+2 \mathrm{e}^{-} \rightarrow 2 \mathrm{Ti}^{2+}+3 \mathrm{H}_{2} \mathrm{O}
$$

In general, the results from EDS and XRD analyses show that all $\mathrm{TiO}_{\mathrm{x}}$ have vanished during the anodizing process of titanium alloy Ti-6Al-7Nb in sulphuric acid solution at the media temperature of $-4^{\circ} \mathrm{C}$, voltage of $20 \mathrm{~V}$ and current of $7.33 \mathrm{Amph}$ with the time for process conduction of $20 \mathrm{~min}$.

\subsection{Microhardness profile of the anodized samples}

Microhardness of the samples was measured by the Metkon MH-3 testing machine with a load of $50 \mathrm{~g}$ for $10 \mathrm{~s}$. All micro hardness data are the average of three measurements. 


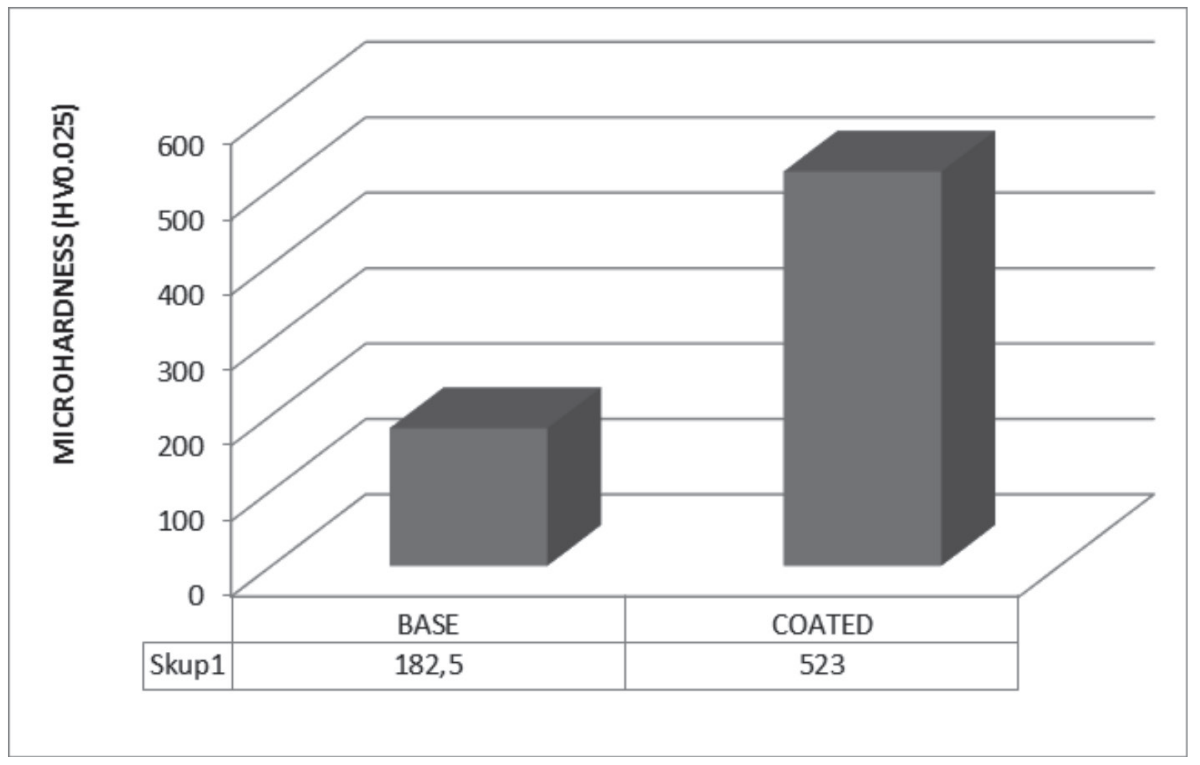

Figure 4 Microhardness profile of the anodized Ti-6Al-7Nb sample

Figure 4 shows the results of microhardness measurements for the obtained anodized layer. It could be indicated that during the anodizing process the microhardness of the surface layer is increased from $182 \mathrm{HV} 0.025$ to $523 \mathrm{HV} 0.025$, as compared to the unanodized (base) Ti-6Al-7Nb. These results can be explained as an aftermath of the anodizing process in sulphuric acid solution, the conduction of which leads to changes in the number of electrons and their equalizing with the number of protons in the nucleus. While performing this reaction, the Ti ions are leaving the crystalline structure. As the result of this procedure, the crystallographic cells' parameters are increased, thus causing the crystallographic structures' tension to increase and to result in increased microhardness $[5,6]$.

\section{Conclusion}

Based on the experimental work and the results obtained in the current paper the following conclusions can be made:

1. Anodizing of titanium alloy Ti-6Al-7Nb at current value of 7.33 Amph, voltage of $20 \mathrm{~V}$ and time of $20 \mathrm{~min}$ in the anodizing media sulphuric acid solution type II (according to SIFCO anodizing instruction manual) at the temperature of $-4^{\circ} \mathrm{C}$ leads to a change in the surface colour and formation of an anodized layer of an average thickness of $4 \mu \mathrm{m}$. 
2. The composition of the anodized surface layer is mainly $\alpha$-Ti and $\beta$-Ti whereas the presence of typical $\mathrm{TiO}_{\mathrm{x}}$ for this type of surface treatment was not indicated.

3 . The anodizing process conducted in this paper leads to increasing the microhardness of Ti-6Al-7Nb from $182 \mathrm{HV} 0.025$ to $523 \mathrm{HV} 0.025$.

\section{References}

1. E. Kobayashi, T. J. Wang, H. Doi, T. Yoneyama, and H. Hamanaka, "Mechanical properties and corrosion resistance of Ti-6Al-7Nb alloy dental castings", Journal of Materials Science: Materials in Medicine, vol. 9, no. 10, pp. 567-574, 1998.

2. E. Krasicka-Cydzik, "Anodic Layer Formation on Titanium and Its Alloys for Biomedical Applications, Titanium Alloys - Towards Achieving Enhanced Properties for Diversified Applications", Dr. A.K.M. Nurul Amin (Ed.), ISBN: 978-953-51-0354-7, InTech, 2012.

3. G. Manivasagam, U. K. Mudali, R. Asokamani, and B. Raj, "Corrosion and microstructural aspects of titanium and its alloys as orthopaedic devices", Corrosion Reviews, vol. 21, no. 2-3, pp. $125-159,2003$.

4. H. Ishizawa, M. Ogino, "Formation and characterization of anodic titanium oxide films containing Ca and P", J. Biomed Mater. Res. 29:65-72, 1995.

5. H. Kim, F. Miyaji, T. Kokubo, S. Nishuguchi, T. Nakamura, "Grade surface structure of bioactive titanium prepared by chemical treatment", J. Biomed Mater. Res. 45:100-7, 1999.

6. H. Takadama, H. Kim, T. Kokubo, T. Nakamura, "An X-ray photoelectron spectroscopy study of the process of apatite formation on bioactive titanium metal" J. Biomed Mater. Res. 55:185-93, 2001.

7. J. L. Delplancke, R. Winand, "Galvanostatic anodization of titanium-II. Reactions efficiencies and electrochemical behavior model", Electrochim Acta 33:1151-9, 1988.

8. L. Bolzoni, E. M. Ruiz-Navas, E. Neubauer, and E. Gordo, "Mechanical properties and microstructural evolution of vacuum hot-pressed titanium and Ti-6Al-7Nb alloy", Journal of the Mechanical Behavior of Biomedical Materials, vol. 9, pp. 91-99, 2012.

9. M. Fellah, M. Labaïz, O. Assala, "Tribological behavior of Ti-6Al-4V and Ti-6Al-7Nb Alloys for Total Hip Prosthesis", Advances in Tribology Volume 2014, 2014.

10. N. Masahashi, Y. Mizukoshi, S. Semboshi, K. Ohmura, and S. Hanada, "Photo-induced properties of anodic oxide films on Ti6Al4V", Thin Solid Films, vol. 520, no. 15, pp. 4956-4964, 2012.

11. Sifco process anodizing instruction manual, Sifco industries Inc., 1997.

12. T. Shibata, YC Zhu, "The effect of film formation condition on the structure and composition of anodic oxide films on titanium", Corros. Sci. 37:253-70, 1995.

13. M. Manov, "Investigation of plasma nitriding process of titanium alloys in non autonomous plasma glow", Ph D thesis, 2013. 